\title{
Qualitative Analysis of Various Determinants in Organizational Design With Special Reference to ITC Limited, India
}

\author{
${ }^{1}$ Shivani M. Mehrotra, ${ }^{* 2}$ Dr. Pingying Zhang \\ ${ }^{1}$ MBA Integrated (Final Year) Student, Shri Ramdeobaba College of Engineering and Management, Nagpur \\ ${ }^{2}$ Assistant Professor at Coggin College of Business, University Of North Florida, FL, USA \\ Email: shivanimehrotra1996@gmail.com,pingying.zhang@unf.edu
}

Received: $20^{\text {th }}$ September 2018, Accepted: $11^{\text {th }}$ October 2018, Published: $31^{\text {st }}$ October 2018

\begin{abstract}
The research examines the organizational design feature of erstwhile Imperial Tobacco Company of India Limited, (ITC Limited) India, to shed light on the growth potential of ITC. We apply a systematic process to address two fundamental design dimensions of an organization: efficiency and effectiveness to assess the design element in (a) goal, (b) strategy, (c) structure, (d) people, and (e) coordination. The company was incorporated on August 24, 1910, and over the past decades, it has become one of the most well-known and profitable organizations in India, as well as a formidable international player due to its robust product portfolio covering both the traditional and greenfield business. This study aims to examine how ITC's organizational structure facilitates the company's growth trajectory in the increasingly competitive domestic and global market.
\end{abstract}

\section{Keywords}

Organizational Design, ITC Limited, Step-by-Step Approach

\section{Introduction}

Organizational design is a step-by-step methodology which identifies dysfunctional aspects of work flow, procedures, structures and systems, realigns them to fit current business realities/goals and then develops plans to implement the new changes. For writing the current paper, the researcher have relied on the book written by Burton Richard M; DeSanctics; Gerardine; Obel, Borge, Titled "Organizational Design: A step by step approach" [1]. It involves two complementary problems, as how to partition a big task of the whole organization into smaller tasks of subunits and how to coordinate these subunit tasks so that they fit together to efficiently realize the bigger task or organizational goals[1]. The models in this book provides for each component, allows to visualize and plot the current location of the organization and then identify the desired point to which one would like the organization to move. In this way, one can see where they are, and where they want their organization to be in the organizational design space [1].

ITC is one of India's most admired and valuable companies with market capitalization of Rs. 3.3 lakh crores. It is the leading Fast Moving Consumer Goods (FMCG) marketer in India and has established several world-class brands in the last 10 years[2].

ITC's aspiration to create enduring value for the nation and its stakeholders is manifested in its robust portfolio of traditional and Greenfield businesses encompassing Fast Moving Consumer Goods (FMCG), Hotels, Paperboards \& Specialty Papers, Packaging, Agri-Business, and Information Technology[2]. This diversified presence in the businesses of tomorrow is powered by a strategy to pursue multiple drivers of growth based on its proven competencies, enterprise strengths and strong synergies between its businesses[2]. The competitiveness of ITC's diverse businesses rest on the strong foundations of institutional strengths derived from its deep consumer insights, cutting-edge Research \& Development, differentiated product development capacity, brand-building capability, world-class manufacturing infrastructure, extensive rural linkages, efficient trade marketing and distribution network and dedicated human resources. ITC's ability to leverage internal synergies residing across its diverse businesses lends a unique source of competitive advantage to its products and services[2]. In this paper, ITC will be considered for the unit of analysis, covering the following aspects-

1) Scope and Goal

2) Strategy

3) Structure

4) People 


\section{Material and Methods}

The researcher has designed this paper relying on the step by step approach. Which is a 'How to' method for outlining a company. Each progression and its sub components give principal building squares to any organization, and guide us through the way toward getting to each building blocks and in addition anticipating change. To simplify continuation in this methodology, the segments of each building square are mapped onto a progression of two-dimensional diagrams that obviously outlines managerial options. The graph are interlocking with the end goal that a particular quadrant in any one graph compares to a similar quadrant in every other graph. Along these lines, one can imagine the relationship among the organizational design components and promptly recognize where there are misfits in the plan.

For the current research, there are 4 parameters chosen on which the company is evaluated. For each parameter, there are $2 \mathrm{sub}$ parameters, which is plotted in 2 by 2 matrix, which actually help to analyze where exactly the company fits in to the graphical representation. The current research is based purely on Secondary data. The data collected is mostly from the official website of ITC Limited, ie. www.itcportal.com. Other source of secondary data is also collected from research papers in Scribd, Business Standards and few news articles from The Economic Times.

\section{Results and Discussion \\ Scope and Goal}

For assessing the relative importance to the organization of two fundamental goal dimensions: Efficiency and Effectiveness. Efficiency is a primary focus on inputs, use of resources, and cost saving. Effectiveness is a focus more on outputs, producing products or services to satisfy the need of customer, employees, stakeholders, or society at large.

\section{Efficiency}

ITC utilizes its resources well. In 1960, ITC helps setup cigarette machines manufacturing and filter rod manufacturing (1963)[3]. The company has achieved total self-sufficiency in cigarette making. The scaled economy greatly improves the operational efficiency of IT.

The company is also well-known for the productivity of its employees. In 2010, ITC's lifestyle retailing business achieved 'Best Supply Chain Practices Awards' for time-effective and cost-effective logistics[4]. The award highlights its efficient logistic practices.

So, to assess where the organization is located on the Efficiency aspect of Figure 1, ITC can be considered high on efficiency.

\section{Effectiveness}

ITC has a strong focus on its product line development. Its diversification strategy back in 1974 due to its rising participation through brand sponsorship with multiple sporting events, ITC Ltd came up with its diversification plan[5].

The company is focused to meet the Social Demands. In 2003, the company turns to water positive by building damns and infotech parks. In 2004, ITC's green center becomes the world's first largest green building to receive LEED Platinum rating[5].ITC also has built up strong connections with the suppliers. In 1911, partnership with farmers in South India for growing Indian Tobacco leaf. In 2000, ITC leveraged information technology for transforming 'E-choupal' initiative[5]. The company is also known to value relations with financiers and stockholders. In 1974, ITC share capital increases from $25 \%$ to $40 \%$ [6].

ITC believes in skill development amongst employees. They came out with capacity development agenda which aims at strengthening organizational capacity through customized training and leadership workshops.

So, to assess where the organization is located on the Effectiveness aspect of Figure 1, ITC can be considered high on Effectiveness. 


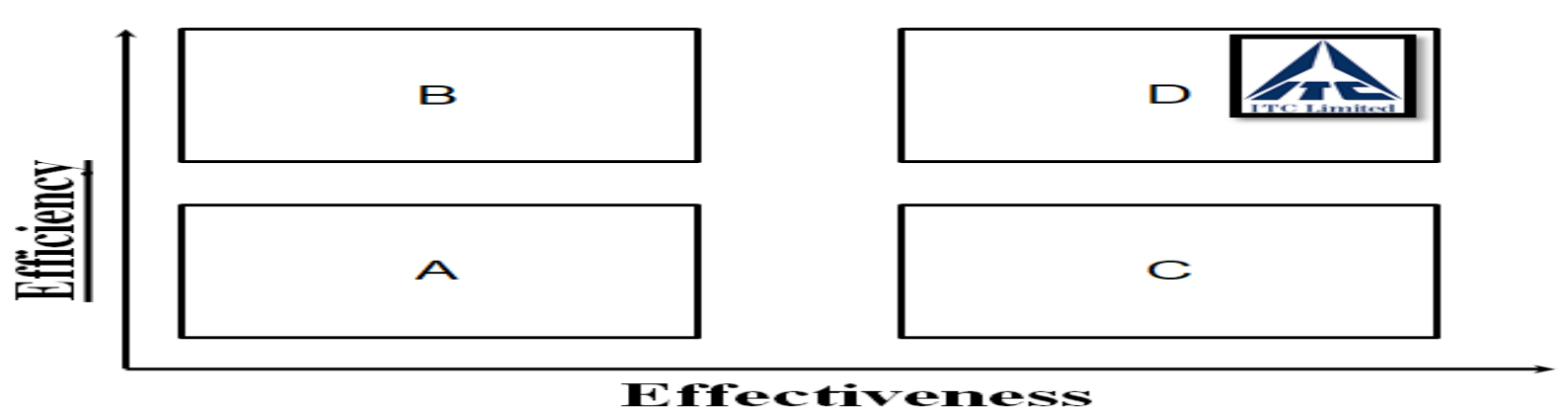

Efiectiveness

Figure 1: The Goal Space

Firm in the D quadrant of goal space graph confront competitive, complex and volatile environments that requires both product innovation and low cost in order to compete successfully. ITC pursue dual goals of efficiency and effectiveness with equal vigor.

\section{Assessing the Strategy}

A firm's strategy is a basic contingency for deciding the organizational design. "Achieving high performance in a business results from establishing and maintaining a fit among three elements; the strategy of the firm, its organizational design, and the environment in which it operates" (Robert, 2004, p.12)

\section{Exploration}

Exploration describes a strategic effort on creativity, innovation, and high quality product. ITC's product offerings have exemplified the idea of creativity and innovation. For example, ITC has successfully entered into wide line of premium range of products under Paperkraft in 2002, such as paperboards, Virgin boards, Recycled boards, specialty boards which includes poly coated, biodegradable barriers. Graphic boards, specialty papers such as Cigarette tissues thin printing, packaging, communication and decor papers. ITC also came up with wide variety in exciting favours in chips, with brand name 'Bingo' which was launched in March 2007 with a wide range of exciting packaged salted snacks. The range includes multiple flavor variants of Potato Chips \& Finger Snacks such as Yumitos salted, cream and onion, masala and tomato. It plans to introduce about 40 new food products in the next year - a record for ITC - and sell premium chocolates and coffee through retail chains and online stores. ITC's foods business is expected to be the majority contributor to its goal of achieving a turnover of Rs 1 lakh crore from its non-cigarette FMCG businesses by 2030. The company is expecting Rs 60,000 crore to Rs 65,000 crore will be generated from the foods business by then (Writankar Mukherjee, ET, April, 2017).

So, to assess where the organization is located on the Exploration aspect of Figure 2, ITC can be considered high on exploration.

\section{Exploitation}

Exploitation describes a strategic effort on process innovation, operational efficiency, and competitive price. ITC aims to outrun Nestle and Britannia as the leader of India's packaged-foods industry in the next two-three years, crowning the two-decade transformation of the century old tobacco giant into a diversified consumer-goods company. (Writankar Mukherjee, ET, April, 2017).In the next two years, ITC plans to implement with the formula of dominance which says acceleration in the introduction of new product. The company also aims to enter in 7-8 newer categories of food business. ITC has made public its interest to enter categories including chocolates launched premium chocolates under Fabelle[7] brand few months ago, dairy through ghee and milk powder, tea and coffee. ITC's competitive advantages over the global leading enterprises in the industry is operational efficiency due to the familiar knowledge in the domestic market such that they could produce products with competitive prices.

So, to assess where the organization is located on the Exploration aspect of Figure 2, ITC can be considered high on exploitation. 


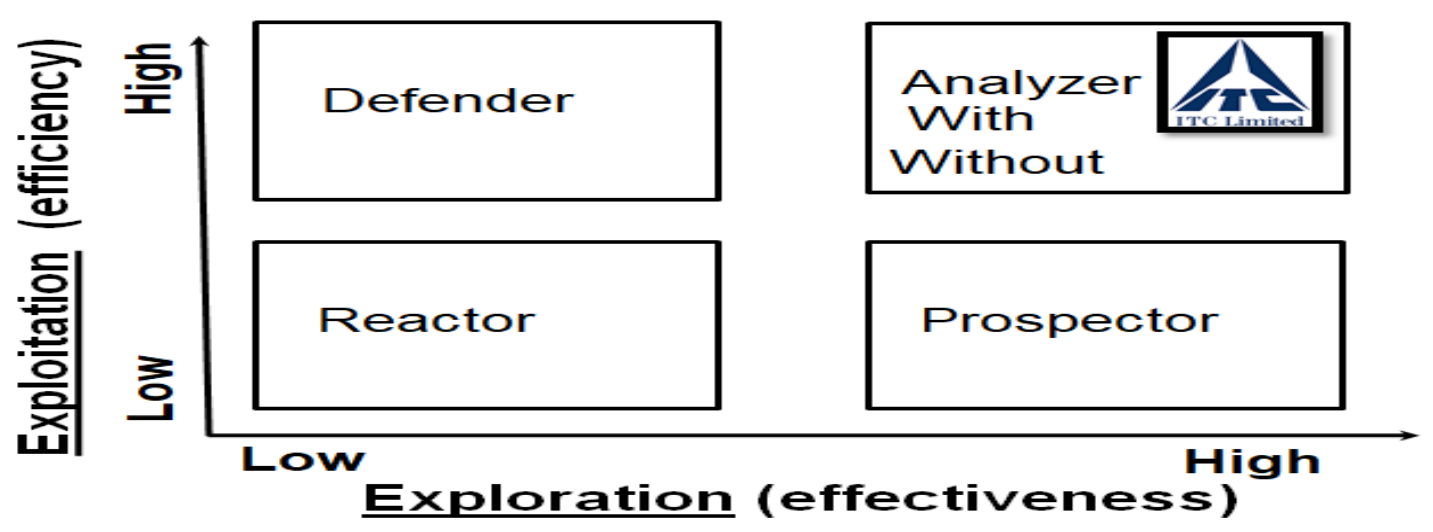

Figure 2: The Strategy Space

ITC will come under the DQuadrant. We believe ITC's strategy on the exploitation and exploration shares an equal weight, suggesting ITC lies on the line between the strategic type of Analyzer with Innovation and the type of Analyzer without Innovation.

\section{Structure}

As the firm grows, the structure changes from simple to complex. There are many internal and external factors that affect the organizational structure. However, the basic aim of the organizational structure is to facilitate corporate objectives effectively and efficiently.

There are mainly four different types of organizational structures, and they are Simple Structure, Functional Structure, Divisional Structure and Matrix Structure. The two dimensions that separate these structures from each other are External Orientation and Functional Specialization. The External Orientation suggests the degree that the total task of a firm is partitioned by the outputs of the firm to generate an external focus. Brand or geographic units are examples. Functional Specialization dimension indicates that the work will be divided by an internal focus exemplified through specialized functions such as R\&D, marketing, operations, etc.

ITC is the company, which has a list of products and sub-brands within. It is complex in nature, and holds the features of divisional kind of structure. It can be observed that ITC is high on External Orientation as the firm has tasks that are being divided according to the outputs. ITC is comparatively low on Functional Specialization as ITC focuses on providing customized products but with similar kind of functional manner and so is the work being divided according to the product and their requirements by the customers.

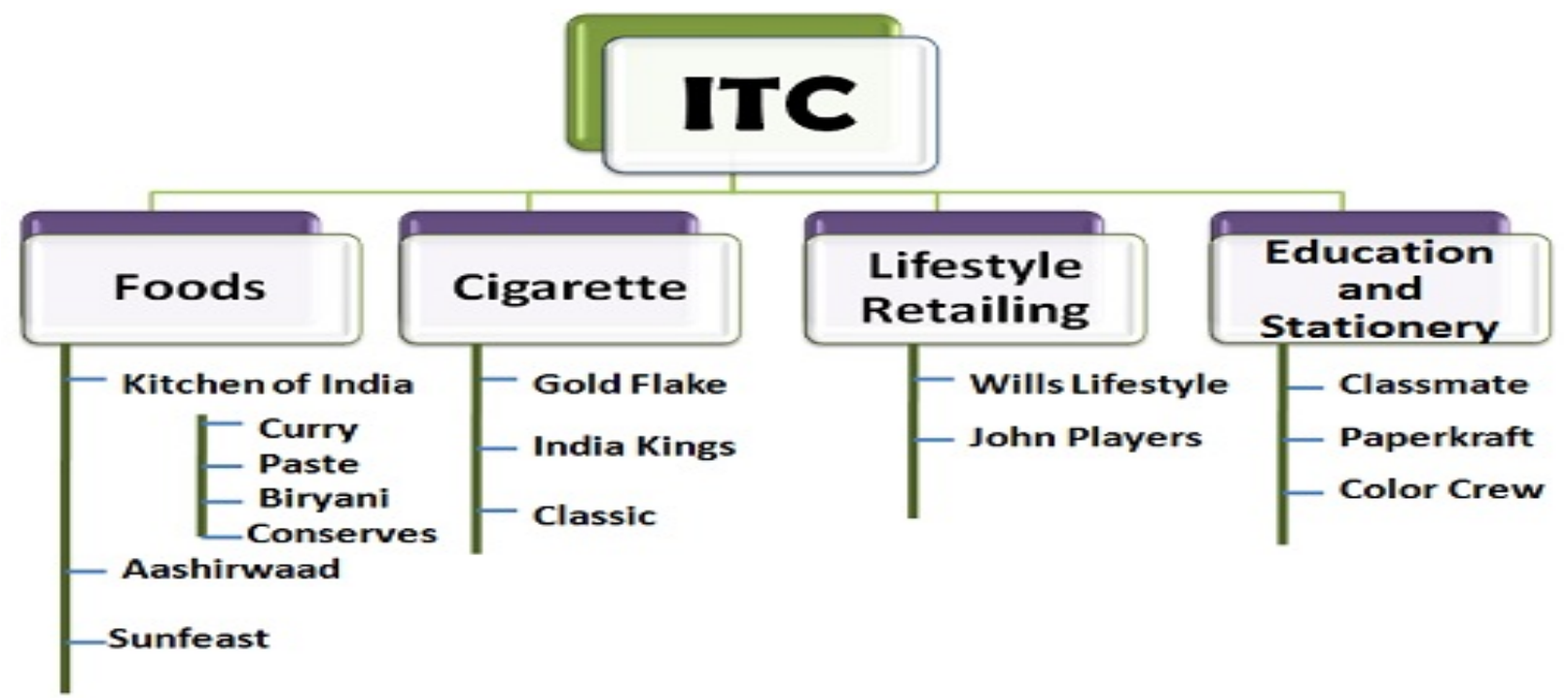

Figure 3: Organogram of ITC [9] 

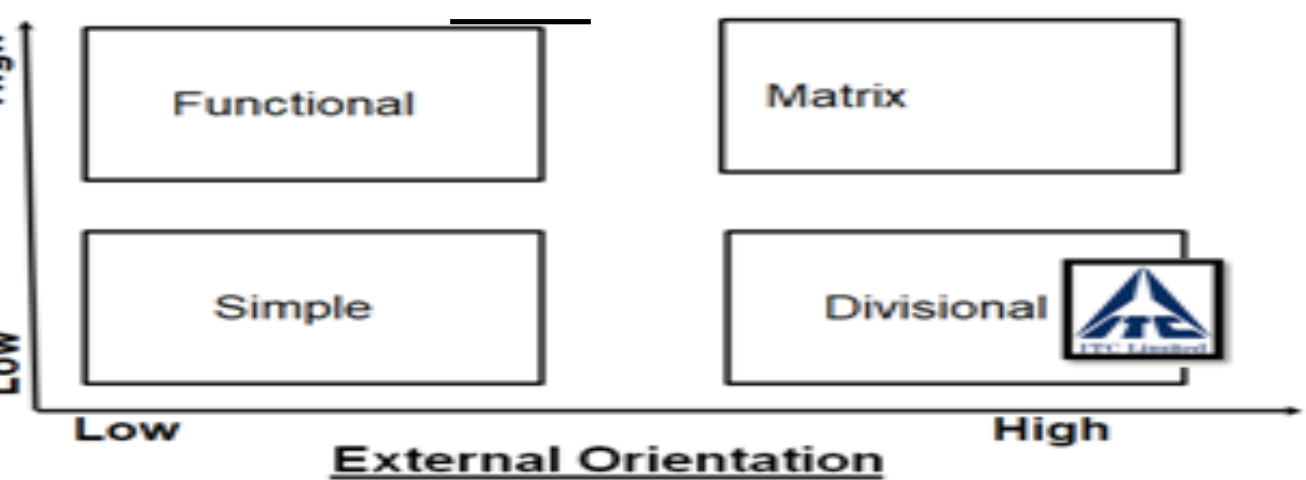

\section{People}

Figure 4: The Structure Space

"An enterprise is its people" so stated the famous Japanese Industrialist Matsushita Konosuke. Like many successful business leaders, Matsushita believe that effective management of people was an essential ingredient to a firm's ability to reach its goal. (PHP Institute, 1994). From the organizational design perspective, there are four typologies of people management that are decided by the dimension of the number of people and the dimension of the degree of professionalization. The number of people and the degree of professionalization measure the basic characteristics of the of the people management in an organization. The number of people is simply a count of all individuals in the firm. Professionalization is a collective skill level of individuals and a measure of their capabilities for the work tasks at hand. Professionalization depends upon employees education, training and experience, i.e their knowledge base, whether accumulated prior to their hire or on the job. If we discuss about ITC, the total number of employees presently working are $25.56 \mathrm{~K}$ in number[8]. This is considerably high in number. If we consider professionalization, the company has $35 \%$ of employees who hold specialized degree and number of years of specialized training and experience[8]. The degree of professionalization reflects the industry characteristics of ITC, where manufacturing and service industry are the main activities.

So, we can analyze, ITC having high number of employees and moderate level of professionalism. Therefore, it stands in the Factory quadrant in the Figure5.

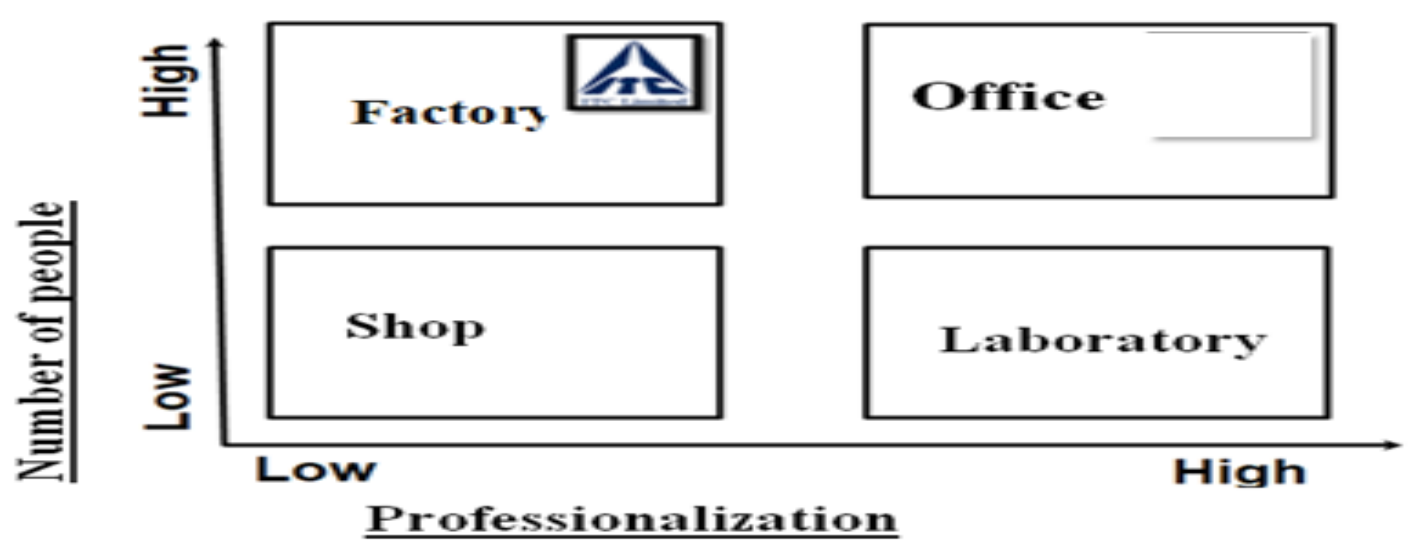

Figure 5: The People space

\section{Conclusion}

What is the appropriate organizational design of goal, strategy, structure, and people management for ITC? One suggestion by Burton and his colleagues [1] is the idea of design fit between design elements. That is, a good design is such that the design elements occupy the same quadrant in the two by two metrics.

From the goal analysis, ITC being high on efficiency and effectiveness is in the ideal state. The strategy space is also in the D quadrant. From this perspective the goal and the strategy of ITC fit with each other. The D quadrant design 
is most complex organizational design to develop and maintain and not all firms are able to take this approach. Nevertheless, when analyzing the structure and people management, misfit occurs. ITC being the rationale player for the divisional configuration aims to be effective with its external focus on the product, customers or region. The structural design in the $\mathrm{C}$ quadrant does not fit the goal nor the strategy in the D quadrant. Similarly, the people management in the B quadrant does not fit with the goal nor the strategy.

What should ITC do? Moving toward the same quadrant would be the recommendation. Given the goal and strategy already in the D quadrant, and given the industries and the business nature of ITC, it would be a good idea to move the structural design toward the D quadrant as well. That is, a matrix structure at the firm level would deliver the strategic focus on both efficiency and effectiveness of ITC. People management could also be potentially pushed toward the D quadrant as well. One practical solution could be that the Human Resource of ITC could help build the middle management team with specialized business degrees in ITC.

\section{Acknowledgement}

With the completion of my research paper entitled "Qualitative Analysis of various determinants in Organizational Design with special reference to ITC Limited, India", I might want to expand my true appreciation and an expression of gratitude to Dr. Rajiv B. Khaire who inspired me to think beyond and to always look for better solutions.

\section{References}

[1] Text Book- A step by step design of Organizational Design by Book by BørgeObel, GerardineDeSanctis, and Richard M. Burton. Ch 1,2,3 7. Pg- 3-80, 122-133

[2] About ITC, creating enduring value for India, https://www.itcportal.com/ (assessed on 22 April, 2018)

[3] ITC Energy Management, Bangalore Cigarette Factory Article (2010), http://www.greenbusinesscentre.com/EES2010/Presentations/National\%20Award-2010/ITC\%20Limited\%20-

\%20Bangalore\%20Cigarattee\%20Factory.pdf

[4] Global Honors, ITC Enduring Values, https://www.itcportal.com/about-itc/global-honours.aspx (assessed on 18 September 18, 2018)

[5] ITC Ltd, by Prawin Sharma, https://www.youtube.com/watch?v=doBm-A5Qg20, published on $15^{\text {th }}$ November 20114

[6] History of ITC Ltd, India, stock performance and news on The Economic Times https://economictimes.indiatimes.com/itc-ltd/infocompanyhistory/companyid-13554.cms

[7] Business of ITC Ltd, in Food and FMCG Segment at Official ITC Information Portal https://www.itcportal.com/businesses/fmcg/foods.aspx

[8] ITC Ltd Number of employees and their level of qualification on Macroaxis.com https://www.macroaxis.com/invest/ratio/ITC.NS--Number-of-Employees

[9] Organizational Structure of ITC Ltd https://businessjargons.com/product-mix.html (Assessed on 18 September 2018) 